\title{
Disseny d'una unitat didàctica sobre la nutrició de les plantes verdes utilitzant un format de pàgina web
}

\author{
Josepa Vert Ros. IES Celrà. jvert@xtec.cat \\ Neus Sanmartí Puig. UAB. neus.sanmarti@uab.cat
}

Presentació de la unitat didàctica "El mercat" adreçada als alumnes de 2n d'ESO en format de pàgina web i seguint les pautes marcades en el nou marc curricular. El material organitzat en quatre blocs conté activitats per als alumnes i les programacions adreçades als professors.

Paraules clau: fotosíntesi, nutrició, vegetal, cooperació, unitat didàctica, pàgina web

\section{Característiques generals de la unitat didàctica}

En del marc d'una llicència d'estudis hem elaborat una unitat didàctica en format de pàgina web (http://www.xtec.cat/ jvert/eso/primer/mercat/portad a/index.htm) tenint en compte el nou marc curricular de la LOE (fig 1).

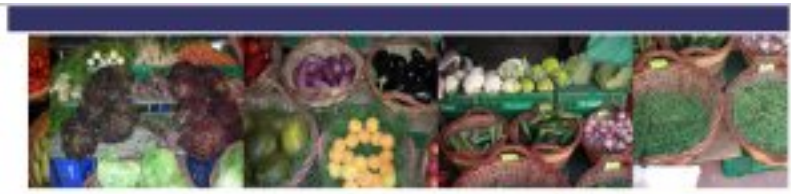

EL MERCAT

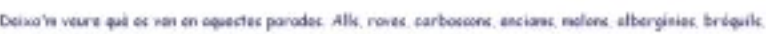

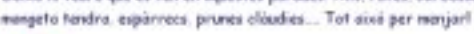

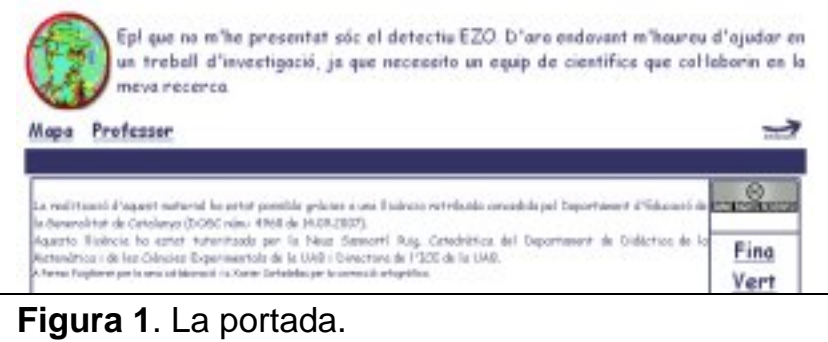

Els nostres adolescents es passen moltes hores davant de pantalles i, en canvi, cada vegada costa més motivar-los en les aules a partir de propostes didàctiques i d'activitats que els enganxin.

Creiem que l'ús de les TIC a l'aula pot facilitar la seva motivació i també la seva implicació en el tre- ball d'aprendre a partir d'interactuar amb els fenòmens, amb els companys $\mathrm{i}$ amb el coneixement. També creiem que els pot ajudar a desenvolupar la seva autonomia, la capacitat de treballar cooperativamet amb els altres, de regular les seves dificultats... En definitiva, que els pot ajudar a ser més competents.

És per això que ens vam decidir a dissenyar una unitat didàctica per a alumnes de $2 \mathrm{n}$ d'ESO utilitzant un format digital. El tema triat va ser la nutrició de les plantes verdes.

Com a context vàrem escollir el mercat, ja que vàrem creure que ens podia servir com a punt de partida amb significat per a tots els alumnes, ja que el mercat és present en totes les cultures.

També vàrem introduir un personatge com a fil conductor: un detectiu, que vol ser tant un element motivador que incideix en el caràcter d'investigació que caracteritza la gènesi de tot coneixement científic, com una ajuda per facilitar la interrelació entre els diferents apartats de la unitat.

Per al disseny hem volgut donar importància als aspectes que considerem bàsics per a l'aprenentatge de les ciències:

- L'observació de fets que succeeixen en l'entorn de l'alumnat i l'experimentació per buscar resposta a les preguntes que ens anem formulant.

- El pensar al voltant de les pròpies idees generades a l'interpretar les observacions i els resultats dels experiments realitzats, tot comparantles amb les de la ciència. 
- La comunicació de les observacions i de les idees, aprofundint en les característiques pròpies del llenguatge de la ciència.

- La combinació de treball autònom i en equip, de manera que els alumnes pensin quines són les seves idees abans de discutir-les en el marc d'un grup.

És per això que el material didàctic busca promoure que els alumnes parlin a la classe explicant les seves idees, escoltant els companys i plantejant-se hipòtesis que hauran de comprovar fent activitats al laboratori virtual i al real, o contrastant-les amb les d'altres o amb informacions recollides a partir de diferents fonts... tot per tal d'anar modificant les idees inicials. També que escriguin textos descriptius, explicatius... ajudant-se amb bases d'orientació per aprendre a utilitzar cada tipus de text en el seu context. Es vol potenciar el treball en equip i, al mateix temps, es dóna temps per al treball individual, de manera que hi ha espais de temps per poder comunicar a tots el que saben, el que volen saber i el que han après.

En tot el procés el professor ajuda a plantejar interrogants i maneres de donar-hi resposta, facilita material per a la realització de les tasques, orienta l'alumnat en el seu treball personal i en les sessions col-lectives. En definitiva, busca que a poc a poc l'alumnat construeixi un model de nutrició de les plantes que sigui vàlid des del punt de vista científic i resulti útil per interpretar fenòmens de la vida quotidiana i per actuar en problemes del seu entorn.

\section{Funció de la pàgina web}

El professor utilitza la pàgina web, d'una banda, com a element motivador i d'una altra, com a suport per al treball d'ensenyament-aprenentatge.

A l'aula, utilitzant una pissarra digital i un vídeoprojector, el grup pot visualitzar tot el contingut de la pàgina, les diferents activitats i les respostes que els alumnes hi van introduint. El professor deixa a la vista de tots l'apartat que es treballa i els alumnes interactuen per donar-hi resposta. També poden disposar de l'activitat impresa i fer-la sobre el paper, i també l'opció de fer-la en un ordinador personal connectat a la xarxa.

Un cop els alumnes han fet l'activitat posen en comú les respostes utilitzant el vídeoprojector. Es discuteixen entre tots i es regulen els aspectes que no s'han fet prou bé o no s'han entès. D'aquesta manera l'activitat de correcció esdevé una activitat d'aprenentatge.
El fet que el material estigui a una pàgina web facilita l'accés dels alumnes a tots els continguts i a les activitats des de qualsevol ordinador connectat a la xarxa. El material es pot imprimir en pdf per tal que l'alumne pugui confeccionar el seu dossier, i també els altres companys poden veure i consultar què han fet $\mathrm{i}$ escrit els companys sempre que s'utilitzi un entorn virtual d'aprenentage (Moodle).

Per facilitar la navegació s'ha utilitzat el color blau en la imatge del detectiu per a les activitats que es considera imprescindibles de fer, mentre que el color verd serveix per identificar les activitats complementàries, que es fan si es creu convenient.

A la mateixa pàgina el professorat pot trobar-hi les programacions de les sessions, els objectius, les activitats, els agrupaments, la gestió a l'aula, el temps i el material que es necessita per dur a terme les diferents activitats. També s'hi pot trobar un model d'examen i algunes preguntes per ampliar.

Per a cada activitat es marca un únic objectiu clau, ja que creiem que d'aquesta manera és més fàcil per al professorat centrar la sessió en funció d'aquest objectiu i controlar-ne l'assoliment.

\section{Organització de la pàgina web i dels blocs d'activitats}

A la pàgina principal (fig. 1) es presenta el títol de la Unitat Didàctica (UD), "El mercat", i també el personatge, el detectiu, que proposa als alumnes que col-laborin com a científics en la recerca a fer.

Des d'aquesta pàgina es pot accedir al mapa del Iloc, que té com a finalitat comunicar el contingut de la unitat i permet accedir directament als quatre blocs que componen la UD, a l'apartat destinat al professor. Si seguim la fletxa, accedim a l'apartat pròpiament de treball.

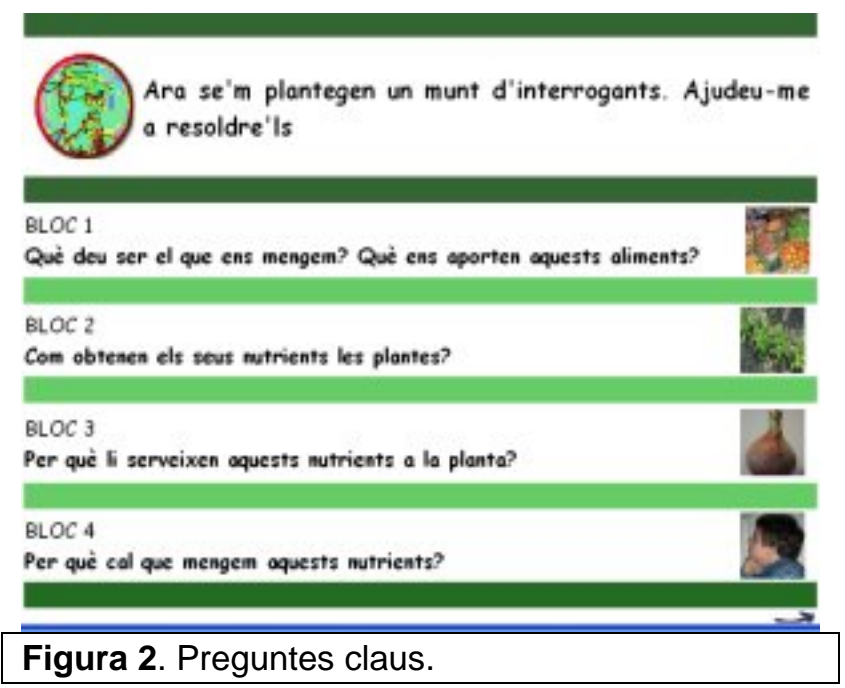


El primer que es troba (fig. 2) són les quatre preguntes que ens planteja el detectiu i que corresponen als quatre blocs que es desenvoluparan al llarg de la Unitat.

- Què deu ser el que ens mengem? Què ens aporten aquests aliments?

- Com obtenen les plantes els seus nutrients?

- Per a què li serveixen aquests nutrients a la planta?

- Per què cal que mengem aquests nutrients?

D'aquesta manera els alumnes saben, de bon començament, què es vol treballar, els objectius del seu treball. Això els dóna seguretat i els ajuda a situar-se i a relacionar els continguts. Sempre que acabem un apartat es planteja un nou interrogant, que és el que s'haurà de resoldre en el següent. D'aquesta manera es van lligant els diferents continguts.

L'activitat que es proposa per començar, en el primer bloc, és una visita al mercat del poble. Aquesta visita es complementa amb una activitat que es farà al laboratori i una altra de cerca d'informació a Internet. Tot plegat ha de servir per respondre els dos primers interrogants: "Què deu ser el que ens mengem? i "Què ens aporten aquests aliments?"

La finalitat és que els alumnes vegin que totes les parts de la planta ens poden servir d'aliment perquè tenen nutrients. En aquesta activitat també pren rellevància el treball en grup, on la seva organització és important per dur a terme la tasca de manera satisfactòria.

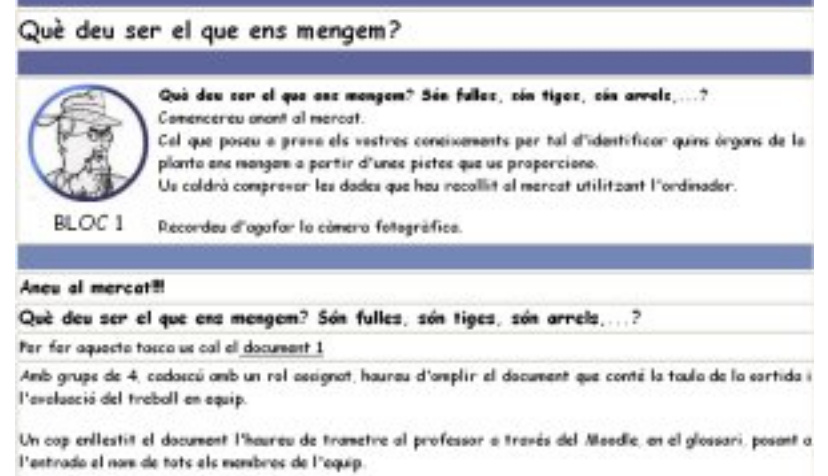

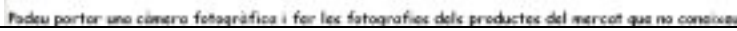

Figura 3. Activitats del bloc 1.

En el segon bloc es planteja la pregunta: "Com obtenen els seus nutrients les plantes?"

Es pretén que els alumnes vegin que la fotosíntesi forma part de la nutrició de les plantes i que durant aquest procés la planta utilitza l'energia de la llum per a la síntesi de nutrients orgànics.
S'inicia amb l'estudi de l'organisme pluricel-lular (nivell macroscòpic) per arribar al nivell cel-lular (nivell microscòpic). A partir de simulacions, de pràctiques de laboratori, de textos sobre experiències de laboratori, d'informacions diverses, i aplicant el mètode científic, els alumnes fan prediccions, se'ls ajuda a interpretar les informacions, a treure conclusions, a formular-se noves preguntes...

En aquest bloc també hi podem trobar activitats complementàries que es faran en funció del criteri del professorat.

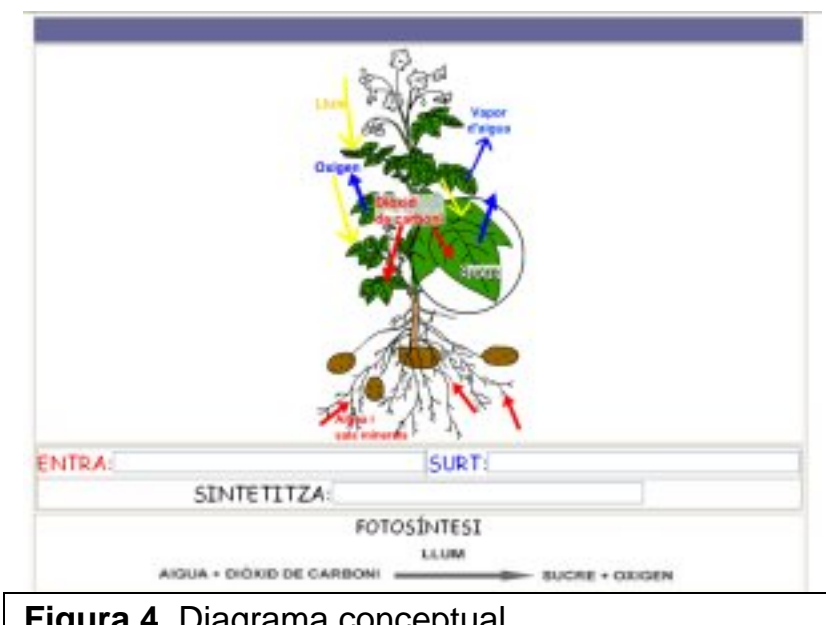

En el tercer bloc la pregunta plantejada és: "Per a què li serveixen aquests nutrients a la planta?".

Es centra en l'estudi a nivell cel-lular i es treballa la necessitat d'energia (respiració cel-lular) i la síntesi d'altres substàncies orgàniques complexes per créixer. Utilitzem una simulació, un quadern virtual i informació. També es fa una revisió de les prediccions formulades a l'inici del segon bloc sobre la nutrició de les plantes.

"Per què cal que mengem aquests nutrients?" És la pregunta que el detectiu ens planteja en el quart bloc.

S'hi estudia la nutrició dels animals identificant les semblances i diferències amb les plantes. També es treballa a nivell macroscòpic i microscòpic. Es proposen activitats d'observació, d'interpretació d'informació, de comparació, de justificació i de conclusió.

En acabar els 4 blocs els alumnes fan una activitat d'aplicació que podríem utilitzar per avaluar els aprenentatges realitzats. Es planteja una situació contextualitzada on els alumnes han d'aplicar el que han après per resoldre-la. En aquest cas hem buscat un tema d'actualitat relacionat amb l'ús de biocombustibles. Hem escollit aquest tema perquè ens interessa que els nostres alumnes s'adonin de la transferència de l'energia de les plantes als animals. 


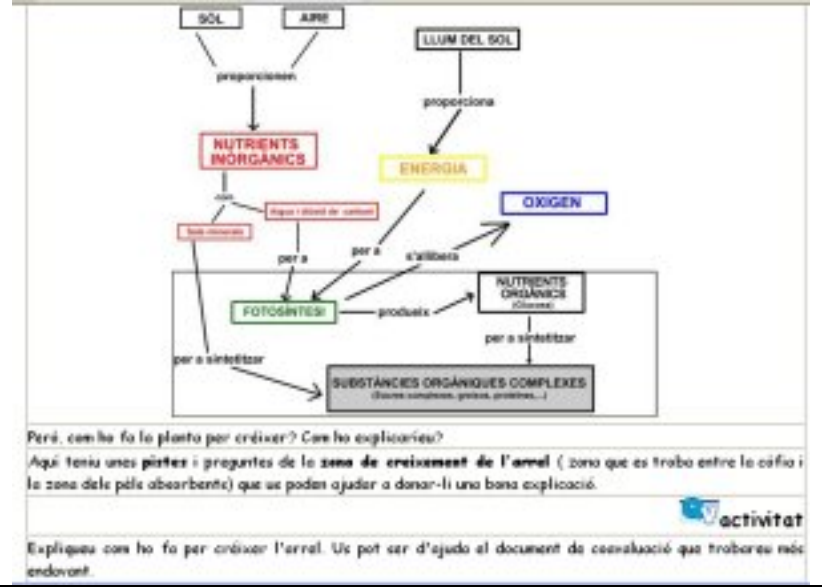

Figura 5. Simulació de les entrades i sortides en una planta.

Al llarg dels 4 blocs es plantegen activitats d'avaluació formadora, tant d'autoavaluació com de coavaluació. Es proposa l'ús d'una taula per poder controlar-se el propi progrés. També l'alumnat disposa de bases d'orientació per a la realització d'algunes tasques i per a l'autoregulació.

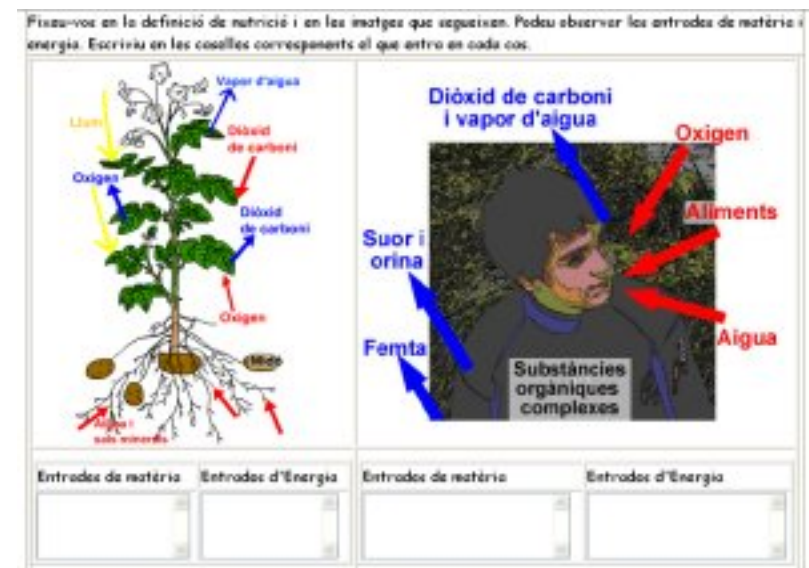

Figura 6. Comparació entre la nutrició animal i la vegetal.

\section{Gestió de l'aula}

Aquest material ha estat pensat per ser utilitzat dins d'una dinàmica de treball a l'aula molt concreta, les principals característiques de la qual són:

- Més que donar informació el professorat planteja interrogants que els alumnes han de resoldre treballant sovint en equip. Els motiva a sentir curiositat i a plantejar-se noves preguntes.

- Els alumnes han d'expressar les idees i arribar a acords per tirar endavant. El professorat té la funció de promoure que posin en qüestió idees expressades que no són idònies i de fer que sorgeixin dubtes. I també gestionar l'intercanvi de punts de vista de manera que sigui enriquidor i no es perdi el temps.

- L'avaluació esdevé activitat d'aprenentatge, responsabilitzant-se de la seva pròpia avaluació i la dels companys.

- Es busca la manera que els alumnes hagin d'aplicar de forma autònoma a noves situacions el que han après.

- Els espais de treball són diversos: l'aula ordinària, el laboratori i l'aula d'informàtica. És necessari poder disposar d'un canó de projecció connectat a un ordinador, per tal que es visualitzin les preguntes i les respostes d'uns i altres, s'introdueixen les esmenes que es van proposant a partir de la discussió, etc.

\begin{tabular}{|c|c|c|}
\hline \multicolumn{3}{|l|}{ Fes l'autoavaluació de la teva explicació } \\
\hline L'explicació perquè sigui cientifica ha de parlar de: & Si & No \\
\hline \multicolumn{3}{|l|}{ El nom del procés } \\
\hline \multicolumn{3}{|l|}{ Totes les substàncies que necessite } \\
\hline \multicolumn{3}{|l|}{ Quins són els nutrients inorgànics } \\
\hline \multicolumn{3}{|l|}{ Quin nutrient és l'orgànic } \\
\hline \multicolumn{3}{|l|}{ On té lloe de la planta } \\
\hline \multicolumn{3}{|l|}{ Els orgànuls de la cel Hula on es realitzo oquest procés } \\
\hline \multicolumn{3}{|l|}{ La font d'energia } \\
\hline \multicolumn{3}{|l|}{ Qui capta l'energia i la transforma } \\
\hline \multicolumn{3}{|l|}{ Formes d'energia (inicial i final) } \\
\hline \multicolumn{3}{|l|}{ Quina substància es sintetitza } \\
\hline \multicolumn{3}{|l|}{ On s'emnogat zema l'energia que es transfereix } \\
\hline \multicolumn{3}{|l|}{ Qué climino } \\
\hline \multicolumn{3}{|l|}{ Perque sigui ben feta thas de fixer si: } \\
\hline \multicolumn{3}{|l|}{ Estd ben redactat } \\
\hline \multicolumn{3}{|l|}{ Fos servir el vocobulari precis } \\
\hline \multicolumn{3}{|l|}{ Fos servir algun dibuix, elgun enquema } \\
\hline Quine puntuoció et poses ( 1 al 15) & & \\
\hline
\end{tabular}

Figura 7. Avaluació.

\section{Reflexions finals}

En aquests moments aquesta unitat s'ha dut a terme amb tres grups d'un institut i se n'ha fet el seguiment per poder-hi fer les modificacions escaients. Els resultats són positius, però ens agradaria poder-los contrastar amb d'altres.

S'ha triat aquest tema perquè el considerem bàsic en el currículum d'ESO i per la seva dificultat, ja que són conegudes les idees alternatives de l'alumnat al voltat de la fotosíntesi.

Creiem que plantejar la UD a través d'una pàgina web té l'avantatge de permetre organitzar molta informació en poc espai. Els alumnes tenen a l'abast, des de qualsevol lloc, la informació ben seqüenciada de la unitat, les activitats que han de fer, les simulacions que els poden ajudar a compren- 
dre-ho, les respostes que han donat a les primeres activitats...

Les dificultats que hem trobat a l'hora de desenvolupar aquest material són fruit de la complexitat del model que ens proposem que els alumnes construeixin, i també de la quantitat d'activitats que es feien necessàries perquè anessin fent seus els diferents continguts. Això contrastava amb la limitació del nombre de sessions disponibles per al seu aprenentatge.

Tot i així cal tenir en compte que es treballen molts més continguts que els relacionats amb el model de nutrició de les plantes verdes. També es promou que l'alumnat aprengui a fer-se preguntes, plantejar hipòtesis, trobar evidències, escriure les seves idees utilitzant el llenguatge científic, treballar en equip, autoregular i co-regular les seves produccions, transferir les idees a la interpretació de situacions diferents de la inicial i a l'actuació. És a dir: es tracta de desenvolupar la seva competència científica.

No cal dir que és un material adaptable, perquè cada professor que l'utilitzi pugui reorientar-lo en funció dels seus objectius i els interessos i necessitats dels seus alumnes i de la comunitat a la qual pertanyen.

\section{Bibliografia}

\section{Sobre Currículum i avaluació}

DEPARTAMENT D'EDUCACIÓ (2007). Currículum educació secundària obligatòria - Decret 143/2007 DOGC núm. 4915. (En línia. Data de consulta: octubre 2007)

http://www.xtec.cat/estudis/eso/curriculum_2007 /ciencies_naturalesa_eso.pdf.

DEPARTAMENTT D'EDŪCACIÓ (2007). Currículum educació secundària obligatòria - Decret 143/2007 DOGC núm. 4915 Annex 1. Competències bàsiques d'ESO. (En línia. Data de consulta: octubre 2007)

http://www.xtec.cat/estudis/eso/curriculum_2007 /competencies_eso.pdf

OECD (2007). Organización para la cooperación y el desarrollo económico. PISA 2006 Marco de la evaluación. Conocimientos y habilidades en Ciencias, Matemáticas y Lectura. (En línia. Data de consulta: novembre 2007) http://www.oecd.org/dataoecd/59/2/39732471.p df

SANMARTÍ, N. (2006). Què ens diu l'informe PlSA? Unes reflexions per millorar com ajudem als nois i noies a aprendre. Centre de Documentació i Experimentació en Ciències i Tecnologia (En línia. Data de consulta: octubre 2007) http://www.coordinadorasc.org/Uploads/docs/inf ormePISA_NeusSenmarti.pps

SANMARTÍ, N. (2006). Conferència: Què ens aporta el concepte de "competència"? ICE Vallès Occidental (En línia. Data de consulta: octubre 2007)

http://antalya.uab.es/ice/sanmarti/materials/com petencies.pdf

SANMARTÍ, N. (2007). 10 ideas clave. Evaluar para aprender. Barcelona: Ed Graó.

\section{Sobre Didàctica de les Ciències}

CDEC (Centre de Documentació i Experimentació en Ciències i Tecnologia,) (2003). Algunes informacions que els mestres haurien de conèixer respecte de les plantes. (En línia. Data de consulta: octubre 2007) http://www.xtec.es/cdec/recursos/pdf/protocol_p $\mathrm{rim} /$ plantes.pdf

JIMÉNEZ ALEIXANDRE, M. P. (coord) I ALTRES (2003). Enseñar ciencias. Barcelona: ed Graó.

SANMARTí, N. (coord) I ALTRES (2003). Aprendre Ciències tot aprenent a escriure ciència. BarceIona: Edicions 62.

SANMARTí, N. (2002). Didáctica de las ciencias en la educación secundaria obligatòria. Madrid: Ed Síntesis.

CAÑAL, P. (1992). Módulos didácticos. 1 ¿Cómo mejorar la enseñanza sobre la nutrición de las plantas verdes y Ciencia? Junta de Andalucía. Consejería de Educación y Ciencia (En línia. Data de consulta: octubre 2007) http://www.juntadeandalucia.es/averroes/publica ciones/55321/libpri15.pdf 